\title{
Residual Renal Function - How Fast Does the Residual Urine Output Function Decline in the First Year of Haemodialysis? - A Scoping Review
}

\author{
Ulrich Steinwandel ${ }^{*}$, Homa Kheirkhah and Hugh Davies \\ School of Nursing and Midwifery, Edith Cowan University, Joondalup, WA, Australia
}

OPEN ACCESS

Edited by:

Michele Provenzano,

University of Catanzaro, Italy

Reviewed by:

Yuri Battaglia,

University Hospital of Ferrara, Italy

Guillermo Garcia Garcia,

Universidad de Guadalajara, Mexico

*Correspondence:

Ulrich Steinwandel

u.steinwandel@ecu.edu.au

Specialty section:

This article was submitted to Clinical Research in Nephrology, a section of the journal

Frontiers in Nephrology

Received: 04 November 2021 Accepted: 23 December 2021 Published: 26 January 2022

Citation:

Steinwandel $\mathrm{U}$, Kheirkhah $\mathrm{H}$ and Davies H (2022) Residual Renal Function - How Fast Does the Residual Urine Output Function Decline in the First Year of Haemodialysis? - A Scoping Review.

Front. Nephrol. 1:808909.

doi: 10.3389/fneph.2021.808909
Background: Haemodialysis is the most common treatment method in Australia for individuals requiring renal replacement therapy. Although it is known that the residual renal function in these patients has many advantages for their overall health outcomes and that the residual urine volume production is also declining over time, it is unknown how fast this functional decline occurs when patients are embarking on their first year on haemodialysis.

Aim: This scoping review sought to determine if the functional decline in renal residual function in the first year of haemodialysis has been previously investigated, documented or quantified.

Method: The scoping review was performed using variety of nursing and medical databases comprising MEDLINE, Embase, Web of Science and CINAHL Plus with Full Text.

Results: The decline of renal residual function in patients on Peritoneal dialysis over the first year of treatment has previously been described, but not in detail for patients receiving haemodialysis. There is a paucity of knowledge how fast residual urine production can decline in patients receiving haemodialysis during their first year of treatment. A PRISMA checklist has been used to validate the results of this scoping review.

Conclusions: The extended preservation of renal residual function in patients on haemodialysis is crucial for their survival and may have a positive impact on their quality of life. An observational study is needed to examine how fast the functional decrease of the residual urine production function within patients receiving haemodialysis generally occurs. This information could prove to be useful in the context of treatment goals and could inform clinical practice.

Keywords: renal residual function, chronic kidney disease, haemodialysis, quality of life, fluid assessment 


\section{INTRODUCTION}

Chronic kidney disease (CKD) is a condition where the function of kidneys is diminished. In 2015, the global burden of the disease (GBD) attributed 1.2 million deaths to kidney failure. The GBD also estimated a further 1.2 million deaths and 18 million years of life lost from cardiovascular conditions directly related to a reduced glomerular filtration rate (GFR) in the kidneys (1). According to the Australian Bureau of Statistics (2), in 20172018 237,800 people in Australia (1\% of the total population) were suffering from CKD. The prevalence of this disease remained unchanged with gender but increased with age (2). In 2017, one in nine deaths were attributed to CKD being an underlying and or an associated cause according to the Australian Institute of Health and Welfare (3). In 2016-17, about 16\% of all hospitalisations were associated with CKD (3). Kidney and urinary diseases accounted for $1.4 \%$ of all diseases in Australia in 2015 (3). Indigenous Australians are 3.6\% more likely to die from CKD than those of non-indigenous descent (3).

Individuals with chronic kidney disease (CKD) require a form of renal replacement therapy (RRT), either haemodialysis (HD), peritoneal dialysis $(\mathrm{PD})$ or a kidney transplant, when they reach stage five of CKD (4). Traditionally, patients will start with RRT when the glomerular filtration rate (GFR) drops below $15 \mathrm{~mL} / \mathrm{min} /$ $1.73 \mathrm{~m}^{2}$ and uremic symptoms of kidney disease prevail (5). Haemodialysis sessions usually aim to restore fluid balance by removing excess fluid via ultrafiltration (UF) and remove metabolic waste products through a convective solute transport (6).

Residual renal function (RRF) in patients receiving dialysis is the residual ability of the kidneys to produce urine and excrete waste products, even when CKD persists. The importance of the RRF for patients on maintenance HD for their survival has often been emphasized (7-10). In addition to improved survival rates, a positive impact on their quality of life has also been reported, when RRF was present $(11,12)$. Further to this, the loss of RRF has also been associated with vascular calcification in HD patients (13), which can also have detrimental consequences on their health (14). Additionally, events of intradialytic hypotension (IDH) occurring while individuals undergo HD sessions have been described as being detrimental to their RRF (15).

Understanding of the RRF status of an individual is not just important for the extra clearance of harmful metabolites that maybe necessary during regular HD sessions (16), but it may also hold essential information about the daily urine volume. This in turn may help to inform fluid-related decision-making processes from patients and clinicians alike. An individualised, patient centred approach for the definition of treatment goals, particularly in regard to UF and excess volume, accounting for unique patient factors may prove to be beneficial for patient outcomes (17). While the knowledge of an individual's current RRF has the potential to influence treatment regimen and treatment (UF) goals over time, it may also affect an individuals' daily fluid intake in between HD sessions and affect their healthrelated quality of life (HRQL) and interdialytic weight gain (1820). Knowledge of an individual's RRF could potentially add significant information for clinicians and patients to lessen disease burden and improve disease management.

Although several studies have described the functional decline of the residual renal function in patients using PD (21, $22)$, there is a paucity of knowledge of the rate of the same functional decline in HD patients during their first year of treatment. With HD being the most common renal replacement therapy (RRT) modality in Australia (78\% in year 2018) (23), this underscores the significance of the potential problem. The ability to quantify functional changes in RRF during the first year of $\mathrm{HD}$, and in particular the residual urine volume (RUV) production ability holds the prospect of informing clinical practice by assisting clinicians to make clinical decisions on regular treatment goals including rate of ultrafiltration (UF) and total ultrafiltration goal (volume) prior to each HD session. So far, previous research has only described that RRF is declining in the first year of HD (24), and little evidence has been provided on how much the RRF is declining and how much this might vary amongst individuals over time.

\section{AlM}

This scoping review aims to provide evidence in peer-reviewed published literature for the rate of functional decline in the urine output of CKD patients starting with maintenance haemodialysis during the first 12 months of treatment. This information could be useful to inform current clinical practice when patients embark on haemodialysis as their ongoing treatment for CKD. It could also potentially lead clinicians to implement novel structural measures to protect their patients' RRF from functional decline in future. The following research question in this scoping review is: "What is the functional decline in urine production within the first 12 months following commencement of HD for end-stage renal disease (ESRD) and how does this affect their quality of life or mortality?"

To facilitate the literature search, the clinical question was addressed using the PICO framework with the following items:

Population: Adult CKD patients with ESRD, aged 18 years and above on maintenance $\mathrm{HD}$ in hospitals and satellite dialysis clinics were included, patients on home HD and pregnant patients were excluded from the search, Intervention: HD, Comparison: Residual Renal Output based on residual urine output volume compared to patients with no residual urine output, Outcomes: Quality of life, mortality.

\section{METHODS}

A scoping literature review was performed in 2021 to search for peer-reviewed journal articles in medical and nursing journals. The search mainly focused on residual renal function of patients within the first 12 months after haemodialysis initiation with emphasis on the residual urine output volume. It was of particular interest if residual urine output function provided a 
specific survival advantage in comparison to individuals with ESRD and no residual urine output. The databases used were CINHAL Plus with Full Text, MEDLINE, Embase and Web of Science. The search terms used included "residual renal function" or "residual kidney function" (= Search term 1 or S1) "haemodialysis initiation" (S2), "haemodialysis and urine output or urine volume" (S3), and "residual renal function and haemodialysis" (S3). The search terms S1, S2, S3 were combined with the term "first year of haemodialysis". Journal articles included in this scoping review were peer-reviewed, full text articles, in English language and published between 2014 and 2021. Additionally, academic journals, renal registries, case reports, non-randomized clinical trials, doctoral dissertations and retrospective audits were included in the overall search. Further, articles and reviews which did not meet minimum quality requirements, without peer review or an abstract were excluded from the review. A PRISMA checklist has been applied to validate the results of this scoping review.

\section{RESULTS}

The primary search in all four databases resulted in 369 nonduplicate citations which were then screened (Figure 1). Applying inclusion and exclusion criteria reduced the number of qualified articles to 59. Another 104 articles were excluded during data extraction, as they did not contain enough statistical data or were as well not considered to be relevant to the research question of residual urine output during the first year of haemodialysis. This scoping literature review resulted in a definitive number of 9 articles which met all characteristics of the inclusion criteria. Table 1 presents a summary of these 15 articles.

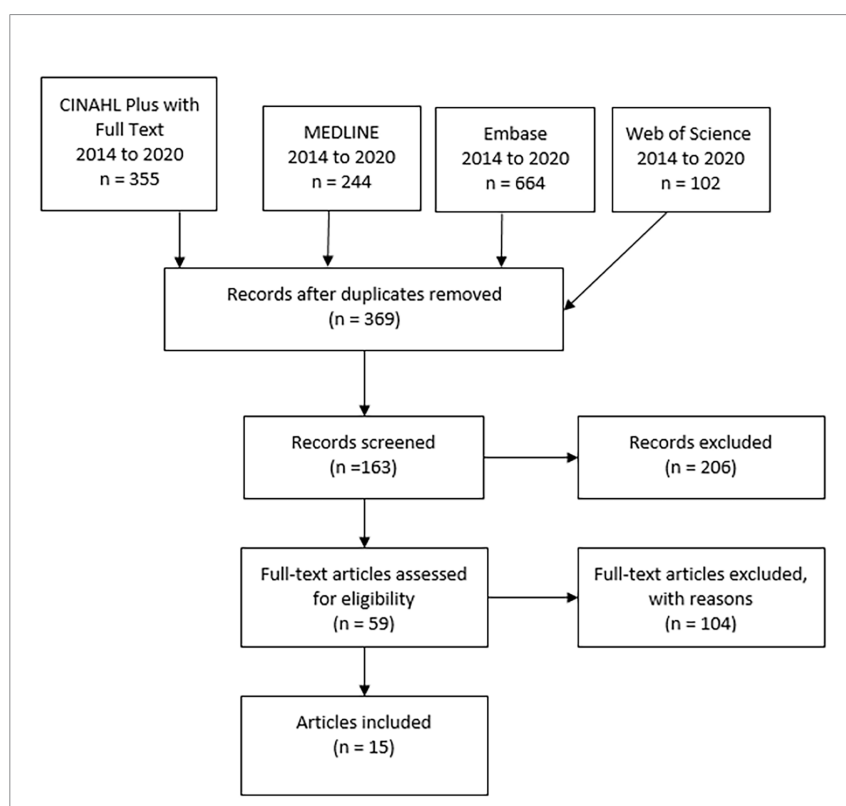

FIGURE 1 | Results of scoping review by searching 4 databases (CINAHL plus, MEDLINE, Embase, Web of Science, PRISMA flowchart.
6 articles were found covering this topic which were either Systematic Literature reviews or Systematic Literature reviews. These articles are presented in Table 2.

\section{RESIDUAL RENAL FUNCTION DURING THE FIRST YEAR OF HAEMODIALYSIS}

Relevant literature concerning urine volume output of patients receiving maintenance $\mathrm{HD}$ during their first year on RRT was examined. No articles quantifying HD patients' declining urine volume during this time period were found, however, several papers have concluded that the RRF rapidly declines during the first year of maintenance HD. There was no further detailed description of this declining RRF found in the current scientific literature or describing specifically the RUV in this particular patient cohort.

An observational study by (26) has concluded that a fast decline in RRF in PD patients resulted in early withdrawal from $\mathrm{PD}$ and conversion to HD treatment, as HD allows for more precise excess volume management. On the other hand, large volume removal (UF goals) during HD may have negative consequences, such as IDH and subsequently a decline in RRF (31). These authors concluded that frequent RRF measurements are essential, as the frequency of HD treatments need to be adjusted according to the patient's RRF status.

A small observational study on seven HD patients by Sjolund, Garcia Anton (28) in the Netherlands has reported that during the first six to 12 months of maintenance HD the mean urine volume reduced at a rate of $1 \mathrm{ml}$ per month. These authors emphasized the beneficial effects of loop diuretics on RRF as their patients were concurrently treated with increasing doses of furosemide during the first 12 months of HD treatment and suggested their use in all incident HD patients. According to their conclusion, this seems to be not a commonly used approach and may vary amongst HD centres globally.

A prospective multicentre study in the United States by You, Kalantar-Zadeh (35) has concluded, that a large proportion of patients commencing with HD have a substantial residual kidney function including urine output and that "some data suggests that haemodialysis patients experience greater preservation of kidney function than previously estimated". These authors have also reported that sometimes $14-20 \%$ of patients still have some RRF after three to five years after transitioning to HD.

Mokoli et al. (30) conducted a historical cohort study, recruiting 250 patients with end stage renal disease (ESRD). The study collected residual urine volume (RUV) over 24 hours at the start, 6 months and 12 months of HD treatments. Patients who had RUV of $>500 \mathrm{ml} /$ day were mostly on diuretics, angiotensin converting enzyme inhibitors (ACEI) with less hypovolemia, hyperkalaemia and anaemia, with higher levels of serum albumin (30), which could prove a survival benefit and affect mortality. The mean RUV values at HD initiation were $680 \pm$ $537 \mathrm{ml} /$ day, $558 \pm 442$ at 6 months and $499 \pm 475$ at 12 months. Decreased urine volume levels were seen in all patients except in patients who did not have any hypertension. Patients who were male, hypovolemic, had chronic tubulointerstitial nephropathy 
TABLE 1 | Summary table of 9 articles: Decline of RRF and urine output volume during the first year of HD.

\begin{tabular}{|c|c|c|c|c|}
\hline & Author (year), Title & Study design & Sample size and sites & Comments/key findings \\
\hline 1 & $\begin{array}{l}\text { Blum, D. (25) "Thinking Volume } \\
\text { First: Developing a Multifaceted } \\
\text { systematic approach to Volume } \\
\text { Management in Haemodialysis." }\end{array}$ & $\begin{array}{l}\text { Case study } \\
\text { presentation }\end{array}$ & $\begin{array}{l}16 \text { patients } \\
\text { HD unit St Michael's Hospital } \\
\text { (Canada) }\end{array}$ & $\begin{array}{l}\text { Local volume management with } 3 \text { components } \\
\text { Volume metric reporting integrated into the routine bloodwork reports. } \\
\text { Abnormal metrics were evaluated using technological testing in the form of } \\
\text { lung ultrasound and bioimpedance spectrometry. Patients with abnormal } \\
\text { metrics for volume were reviewed and educated by the multidisciplinary team. }\end{array}$ \\
\hline 2 & $\begin{array}{l}\text { Wang, J. et al. (26) "A fast } \\
\text { decline of residual renal function } \\
\text { in the first year is a predictor for } \\
\text { early withdrawal from peritoneal } \\
\text { Dialysis in Non-diabetic } \\
\text { patients." }\end{array}$ & $\begin{array}{l}\text { Observational } \\
\text { study }\end{array}$ & $\begin{array}{l}567 \text { patients at First Affiliated } \\
\text { Hospital Zhejiang (China) who } \\
\text { started with PD between } 2005 \\
\text { and } 2013\end{array}$ & $\begin{array}{l}\text { Faster RRF decline in the first year was a predictor for all-cause mortality and } \\
\text { conversion to HD in non-diabetic PD patients }\end{array}$ \\
\hline 3 & $\begin{array}{l}\text { Lee et al. (27) "Ultrafiltration rate } \\
\text { effects declines in residual } \\
\text { kidney function in hemodialysis } \\
\text { patients." }\end{array}$ & $\begin{array}{l}\text { Retrospective } \\
\text { cohort study }\end{array}$ & $\begin{array}{l}\text { 7, } 753 \text { patients who initiated } \\
\text { conventional hemodialysis from } \\
2007 \text { to } 2011 \text { (United States) }\end{array}$ & $\begin{array}{l}\text { Higher UFR was associated with a rapid decline in residual renal function } \\
\text { among conventional hemodialysis patients. }\end{array}$ \\
\hline 4 & $\begin{array}{l}\text { Obi et al. (9) "Residual kidney } \\
\text { function decline and mortality in } \\
\text { incident hemodialysis patients." }\end{array}$ & $\begin{array}{l}\text { Longitudinal } \\
\text { study }\end{array}$ & $\begin{array}{l}6538 \text { patients (2007 to } 2010 \text { ) } \\
\text { (California, United States) }\end{array}$ & $\begin{array}{l}\text { Only a few studies have explored RKF in patients on HD. RKF contributes to } \\
\text { adequate solute clearance. Data at baseline and } 1 \text { year after HD initiation } \\
\text { reported gradient association between RKF loss and all-cause mortality. } \\
\text { Clinical benefits of RKF preservation methods are yet to be determined. }\end{array}$ \\
\hline 5 & $\begin{array}{l}\text { Shafi et al. (8) "Residual kidney } \\
\text { function: Implications in the era } \\
\text { of personalised medicine." }\end{array}$ & Case study & (Amsterdam, Netherlands) & $\begin{array}{l}\text { Residual kidney function is essential for improved outcomes of PD and HD. } \\
\text { After dialysis initiation, RKF provides volume and solute clearance necessary } \\
\text { to remove toxins that cannot be removed using conventional dialysis } \\
\text { methods. The management of uremia can be personalized due to the benefits } \\
\text { of RKF, taking into account the solute, volume and quality of life needs. }\end{array}$ \\
\hline 6 & $\begin{array}{l}\text { Silva et al. (20) "Coping with } \\
\text { fluid restriction and the quality of } \\
\text { life in hemodialysis patients with } \\
\text { very low or no daily urine } \\
\text { output." }\end{array}$ & $\begin{array}{l}\text { Cross } \\
\text { sectional } \\
\text { study }\end{array}$ & $\begin{array}{l}271 \text { Brazilian adult maintenance } \\
\text { hemodialysis patients } \\
\text { (Brazil) }\end{array}$ & $\begin{array}{l}52.4 \% \text { of the participants reported being moderately to extremely bothered by } \\
\text { fluid restriction and had lower scores for health-related quality of life. Increased } \\
\text { fluid restriction decreases quality of life. An improvement in fluid restriction } \\
\text { methods can improve quality of life in HD patients. }\end{array}$ \\
\hline 7 & $\begin{array}{l}\text { Sjolund et al. (28) "Diuretics, } \\
\text { limited ultrafiltration, and residual } \\
\text { renal function in incident } \\
\text { hemodialysis patients: A case } \\
\text { series." }\end{array}$ & Case series & $\begin{array}{l}7 \text { hemodialysis patients } \\
\text { (The Netherlands) }\end{array}$ & $\begin{array}{l}\text { During the first } 6 \text { to } 12 \text { months the mean urine volume was reduced by } 1 \mathrm{ml} \\
\text { per month, residual GFR declined by } 0.03 \mathrm{ml} / \mathrm{min} / 1.72 \mathrm{~m}^{2} / \mathrm{month} \text {. The mean } \\
\text { rate of decline for urine volume from } 12 \text { to } 24 \text { months was } 33 \mathrm{ml} / \mathrm{month} \text { and } \\
\text { residual GFR was } 0.02 \mathrm{ml} / \mathrm{min} / 1.72 \mathrm{~m}^{2} / \mathrm{month} \text {. The low rate decline is due to } \\
\text { the effects of diuretic (frusemide) during the first } 2 \text { years of HD initiation. }\end{array}$ \\
\hline 8 & $\begin{array}{l}\text { Poulsen et al. (29) "Quality of life } \\
\text { development during initial } \\
\text { haemodialysis therapy and } \\
\text { association with loss of residual } \\
\text { renal function." }\end{array}$ & $\begin{array}{l}\text { Questionnaire } \\
\text { (Kidney } \\
\text { Disease } \\
\text { Quality of Life } \\
\text { Short Form } \\
\text { Version 1.3) }\end{array}$ & $\begin{array}{l}82 \text { patients at } 6 \text { months and } 12 \\
\text { months of dialysis treatment } \\
\text { (Denmark) }\end{array}$ & $\begin{array}{l}\text { The use of Irbesartan did not affect Health Related Quality of Life (HRQL). } \\
\text { Decline in GFR correlated with decreased HRQL over time. Preservation of } \\
\text { residual renal function is important for HRQL, which is also negatively affected } \\
\text { by comorbidities such as diabetes, hospital admissions, female gender and } \\
\text { age. }\end{array}$ \\
\hline 9 & $\begin{array}{l}\text { Mokoli et al. (30) "Factors } \\
\text { associated with residual urine } \\
\text { volume preservation in patients } \\
\text { undergoing haemodialysis for } \\
\text { end-stage kidney disease in } \\
\text { Kinshasa." }\end{array}$ & Cohort study & $\begin{array}{l}250 \text { patients with ESRD } \\
\text { undergoing haemodialysis } \\
\text { between January } 2007 \text { and July } \\
2013 \text { in two haemodialysis } \\
\text { centres in Kinshasa, Democratic } \\
\text { Republic of Congo }\end{array}$ & $\begin{array}{l}\text { ACE inhibitors, chronic tubulointerstitial nephropathy and left ventricular } \\
\text { hypertrophy reduction emerged as the main independent predictors of } \\
\text { residual urine volume preservation over time, and in particular in the first year } \\
\text { of dialysis. }\end{array}$ \\
\hline
\end{tabular}

and those who were treated with diuretics and ACEI and angiotensin receptor blockers (ARB) had a higher median urine volume (36). The study concluded that RRF declines over 12 months of HD treatments. Preservation of RRF was significantly associated with ACEI and interstitial nephropathy. On the other hand, the loss of RRF was associated with the presence of left ventricular hypertrophy $(\mathrm{LVH})$ at the initiation of $\mathrm{HD}$ treatments (36). The main limitation in this study was the relatively small sample size and the retrospective characteristics that hindered setting up a cause-effect relationship. Despite the limitations, this study is one of the few that has used RUV collections to measure the decline in RRF over 12 months of HD treatments. The incorporation of the RRF into the HD prescriptions has potential to aid in preserving residual kidney function in the long term. Most clinics do not measure RRF due to the difficulty of timed urine collection and therefore the patient does not receive personalised HD prescription that may aid in the preservation of RRF (37). Wong et al. (37) explored methods of measuring RRF without urine collection. The study concluded that timed urine collections can be very challenging and instead the use of biomarkers to determine cut off levels of residual urea clearance may be a better and promising method. You, Kalantar-Zadeh (35) have reported correspondingly that frequently measuring 24 -hour urine collection is onerous and assessment of patient-reported urine volume may help in the day-to day management of $\mathrm{HD}$ and can be easily implemented at the patient's bedside. 
TABLE 2 | Summary table of 6 articles, either Literature Reviews or Systematic Literature reviews: Decline of RRF and urine output volume during the first year of HD.

\begin{tabular}{|c|c|c|c|c|}
\hline & Author (year), Title & Study design & Sample size and sites & comments/key findings \\
\hline 1 & $\begin{array}{l}\text { Huang, S. et al. (31) } \\
\text { "Euvolemia in haemodialysis } \\
\text { patients: A potentially } \\
\text { dangerous goal?" }\end{array}$ & $\begin{array}{l}\text { Literature } \\
\text { review }\end{array}$ & $\begin{array}{l}12 \text { articles (1999 to } \\
\text { 2016) (United } \\
\text { Kingdom) }\end{array}$ & $\begin{array}{l}\text { Patient characteristics such as RRF, adequate volume control, lack of significant } \\
\text { anaemia/electrolyte imbalance, satisfactory health related quality of life, low comorbid } \\
\text { disease burden, and good nutritional status. Regular RRF measurements is essential, } \\
\text { because HD frequency needs to be adjusted depending on the patient's RRF status. }\end{array}$ \\
\hline 2 & $\begin{array}{l}\text { Kong, Davies, \& Mount (24) } \\
\text { "The importance of residual } \\
\text { kidney function in dialysis } \\
\text { patients." }\end{array}$ & $\begin{array}{l}\text { Systematic } \\
\text { literature review }\end{array}$ & $\begin{array}{l}\text { Articles from } 2017 \text { to } \\
2018 \text { (Victoria, } \\
\text { Australia) }\end{array}$ & $\begin{array}{l}\text { Over } 80 \% \text { of patients have some levels of residual renal function present at the start of } \\
\text { dialysis treatments. There is a decline over the years, however, up to } 30 \% \text { of patients } \\
\text { after } 5 \text { years of HD still have a measurable level of RRF. In HD patients, RRF is usually } \\
\text { disregarded. To maintain and maximize RRF in HD patients, further research is needed. }\end{array}$ \\
\hline 3 & $\begin{array}{l}\text { Mathew, A.T. (17) "Incremental } \\
\text { dialysis for preserving residual } \\
\text { kidney function: Does one size } \\
\text { fit all when initiating dialysis?" }\end{array}$ & $\begin{array}{l}\text { Literature } \\
\text { review }\end{array}$ & $\begin{array}{l}12 \text { observational } \\
\text { cohort studies } \\
\text { (California, United } \\
\text { States) }\end{array}$ & $\begin{array}{l}\text { Haemodialysis is usually initiated on } 3 \text { times per week, regardless of residual kidney } \\
\text { function. As RKF is associated with numerous benefits for the patients, it is essential for } \\
\text { HD treatments to be personalized, taking into account the individual RKF. Incremental } \\
\text { HD prescriptions are recommended in this case, as HD initiation is less frequent and } \\
\text { allows for regular measurement of RKF. }\end{array}$ \\
\hline 4 & $\begin{array}{l}\text { OK et al. (32) "Interplay of } \\
\text { volume, blood pressure, organ } \\
\text { ischemia, residual renal } \\
\text { function, and diet: Certainties } \\
\text { and uncertainties with dialytic } \\
\text { management." }\end{array}$ & $\begin{array}{l}\text { Literature } \\
\text { review }\end{array}$ & (Turkey) & $\begin{array}{l}\text { Both blood pressure and volume control are managed poorly in HD patients which } \\
\text { causes the increased morbidity and mortality. Restriction of dietary salt intake, increased } \\
\text { frequency, and/or duration of haemodialysis sessions or addition of temporary extra } \\
\text { sessions during the process of gradually reducing post- dialysis body weight in } \\
\text { conventional HD and discontinuation of antihypertensive medications could prevent } \\
\text { these complications. }\end{array}$ \\
\hline 5 & $\begin{array}{l}\text { Mitema \& Jaar (33) "How can } \\
\text { we improve the quality of life of } \\
\text { dialysis patients." }\end{array}$ & $\begin{array}{l}\text { Literature } \\
\text { review: review } \\
\text { of various } \\
\text { Health-Related } \\
\text { Quality of Life } \\
\text { (HRQOL) tools }\end{array}$ & (United States) & $\begin{array}{l}\text { There are multiple validated tools which can be used to improve HRQOL in ESRD } \\
\text { patients. Each tool should be used in an individualized manner to address specific } \\
\text { dialysis patient needs such as anaemia, depression sexual dysfunction, sleep related } \\
\text { disorders and the preservation of residual kidney function. }\end{array}$ \\
\hline 6 & $\begin{array}{l}\text { Fang et al. (34) "Residual renal } \\
\text { function among patients on } \\
\text { haemodialysis and implications } \\
\text { for clinical practice." }\end{array}$ & $\begin{array}{l}\text { Systematic } \\
\text { Literature } \\
\text { review }\end{array}$ & $\begin{array}{l}4 \text { databases searched } \\
\text { for relevant information } \\
\text { between } 200 \text { and } 2018 \\
\text { (Medline, CINAHL Plus, } \\
\text { Embase and Pubmed) }\end{array}$ & $\begin{array}{l}\text { Nephrology nurses can improve clinical practice to assist preserving RKF in HD patients } \\
\text { through preventing intradialytic hypotension, improving dry weight assessment and } \\
\text { volume control, advocating for incremental HD, promoting haemodiafiltration and other } \\
\text { measures }\end{array}$ \\
\hline
\end{tabular}

\section{QUALITY OF LIFE AND RESIDUAL RENAL FUNCTION}

Another major factor in the discussion about RRF is its impact on the Quality of Life (QOL) in HD patients. A publication by Mitema and Jaar (33) has investigated a variety of validated tools which are readily available to assess HD patients QOL. They have recommended to use each tool in an individualized manner to address specific patient needs and recommended to include the preservation of the RRF. These authors also reported from patients with self-reported urine output at baseline of at least $250 \mathrm{ml} /$ day were reporting better social functioning, vitality, cognitive functioning and quality of life over a year. Poulsen et al. (18) surveyed $82 \mathrm{HD}$ patients using the Kidney Disease Quality of Life Short Form Version 1.3 (KDQOL-SFTM) at the start of treatment, at six and 12 months. The study concluded that health related quality of life (HRQOL) is largely impacted in patients receiving HD treatment. Although the patient can become used to the HD and this could lead to an improved HRQOL. However, other debilitating factors such as multiple side effects of $\mathrm{HD}$, frequent hospitalisation, diabetes and the decline in RRF after 12 months can eventually lead to a further decrease in HRQOL (18). Decreasing glomerular filtration rate (GFR) was measured by collecting urine for 24 hours at baseline, 6 and 12 months in this study. A decreasing GFR in patients with CKD also lowers HRQOL, was concluded by these authors. Other studies have found a marked correlation between decreased urine volume and a decreased quality of life. The lower HRQOL is associated with increased restrictions in diet, fluids, and the duration of dialysis sessions as the RRF declines $(18,20)$. Kong, Davies and Mount (24) conducted a literature review to explore the relationship between RRF and the outcomes for patients on HD treatment. The study found that the preservation of RRF, even at very low levels, contributes to increased quality of life and patient survival (24).

\section{RESIDUAL RENAL FUNCTION PRESERVATION}

In a longitudinal cohort of 6538 patients, Obi et al. (9) aimed to determine the existing clinical factors at HD initiation that predict the preservation of RRF at 1 year of HD treatments. The study also included quantitative investigations of the association in the annual change of RRF with survival. The study found that greater renal urine clearance (CLurea) after 1 year of HD treatments, which lead to better survival rates. Factors such as being female, non-white races, history of congestive heart failure $(\mathrm{CHF})$ and diabetes were the main factors which were associated with RRF decline in the first year of HD (9). The median baseline urine volume was $900 \mathrm{ml} /$ day and the median volume at 1 year was 650 $\mathrm{ml} /$ day. These authors also observed a significant trend toward lower mortality at higher urine volume. Several limitations existed in this study with the most important one being the inaccuracy of 
RRF measurements, using the (CLurea) instead of the average renal urea and creatinine clearance. Complete urine collection samples were also challenging in terms of timing. Patients who were treated with PD, nocturnal HD or Home HD were excluded from the study although they might have had presented with different RRF (9).

In HD patients, RRF can contribute to removal of sodium and improved volume control, leading to a reduced interdialytic weight gain. Left ventricular hypertrophy and left ventricular systolic dysfunction are less severe with the presence of RRF. Residual renal function is also associated with higher serum albumin and correlates to a better nutritional status in $\operatorname{HD}$ patients $(24,38)$. Mathew et al. (17) have emphasized the importance of regular RRF measurements in order to allow the use of incremental HD in case of a decline in RRF. The difficulty in accurate measurement of the interdialytic urine levels is thought to be the main reason that only $5 \%$ of HD patients have measured RRF levels. Higher RRF at one year of dialysis has been associated with higher survival rates (17). Studies have suggested the preservation of RRF may be possible with a twice weekly HD regimen, compared to the routine thrice weekly which was associated with a loss of RRF that was seven times higher $(17,39)$.

A systematic literature review by Fang, Lunardi (34) has indicated that renal nurses have multiple options to improve clinical practice which may assist in preserving RRF in HD patients through a variety of measures. This includes the prevention of intradialytic hypotension, improving measures for dry weight or ideal body weight assessments, volume control, advocating for incremental HD, promoting haemodiafiltration (HDF) as a treatment option and other measures.

\section{DISCUSSION}

In the HD population, volume overload and hypovolemia are common debilitating symptoms which can increase hospitalisation, leading to a reduced quality of life (25). Volume overload can cause cardiovascular events, dyspnoea and left ventricular remodelling which can eventually lead to death (40). Hypovolemia on the other hand causes organ ischemia, fatigue and changes in cognitive functioning $(25,32)$ while organ ischemia may subsequently lead to loss of residual renal function (32). Blum et al. (25) suggested three main volume management strategies that will help clinicians determine patient's true volume status. The first strategy was to integrate the reporting of volume metric into the routine bloodwork report. The use of technology such as bioimpedance and lung ultrasound along with traditional tests can aid in volume assessment and review and assessment of abnormal volume metrics by the multidisciplinary team. The study identified 16 patients with abnormal volume metrics where the volume dysfunction was related to either a high intradialytic weight gain, incorrect target weight gain or missed sessions of $\mathrm{HD}$ treatment (25). The patients were tracked at 6-week intervals with the goal of reducing the prevalence of abnormal volume metrics by targeting the root causes. The study concluded that the use of the three volume management strategies can personalise HD treatments and improve volume status in patients (25). The study had several limitations including the tracking of the patients in 6-week intervals and not in real time and the use of recommended technological adjuncts being limited to the availability of trained staff (25). A recent multicentre randomized controlled trial study by (41) has demonstrated the efficacy of a lung ultrasound-guided treatment strategy when assessing patients for fluid overload and determining ultrafiltration goals. This highlights the need for qualified and appropriately trained healthcare professionals, which potentially will be in most situations the renal nurses who are caring for HD patients attending their treatments.

HD has often been described as being associated with being more successful in attaining euvolemia than PD, but also with a more rapid loss of residual renal function (42) which may be detrimental for the patient's survival (8).

A study by Lee, Okuda (27) has indicated that a higher ultrafiltration rate (UFR), which equals the ultrafiltration in millilitres per hour of HD treatment, has been observed as associated with rapid decline in RRF and also increased mortality among conventional HD patients. It can therefore be assumed that the lower the UFR is, the less detrimental effect the UFR may have on the RUV in the long term.

\section{IMPLICATIONS FOR PRACTICE}

- Renal nurses are the primary healthcare professionals caring for patients starting on maintenance HD and must be made aware and receive more specific education about the importance of maintaining RRF and RUV in HD patients, specifically during the first year on HD

- Regular RUV measurements in patients starting with HD may hold essential information to inform clinicians when deciding on regular treatment (UF) goals

- Knowledge of the individual parameters of RUV may have positive implications for HRQOL and provide better health outcomes for HD patients starting with $\mathrm{HD}$

- Increasing doses of loop diuretics during the first year of HD, such as furosemide, may be preservative for the RRF and RUV.

- Observing of patient-reported urine volume may provide for better fluid management and may support preserving RRF and RUV in patients on HD.

\section{CONCLUSION}

This literature review has demonstrated, that preserving RRF and RUV for as long as possible has multiple positive implications on the health-related quality of life (HRQOL) and on the morbidity in HD patients. This is essential and important, especially the longer this RRF is maintained. No study was found which had either observed, documented, or quantified the loss of RUV in a detailed description over the first 12 months of maintenance HD and/or any correlation to goals of treatment in terms of removal 
TABLE 3 | Potential future studies resulting from this scoping review.

An observational study on the functional decrease of the renal residual Study 1 function including urine production in haemodialysis patients during their first year of treatment

An observational study on the current clinical practices and methods Study 2 of fluid assessment and ultrafiltration goals in haemodialysis units What is the current clinical practice of renal nurses in terms of preserving the renal residual function in patients on haemodialysis - An observational study

Which factors may cause the decline of the renal residual function and Study 4 the urine production in haemodialysis patients?

of excess fluid (UF). This critical information could potentially be very useful and has potential to inform clinical practice on an individual patient level. Future research should be undertaken to observe this common change in RRF including urine production during the early stages of maintenance $\mathrm{HD}$, to provide essential knowledge to clinicians and patients alike. This information could have potential to impact on HRQOL and health outcomes for HD patients.

\section{LIMITATIONS AND FUTURE STUDIES}

Renal nurses who are caring for patients starting on maintenance haemodialysis must be made aware and receive more education

\section{REFERENCES}

1. Luyckx V, Tonelli M, Stanifer J. The Global Burden of Kidney Disease and the Sustainable Development Goals. Bull. World Health Organisation (2017) 96 (6):369-440. doi: 10.2471/BLT.17.206441

2. Australian Bureau of Statistics [ABS]. Kidney Disease (2019). Available at: https://www.abs.gov.au/ausstats/abs@.nsf/Lookup/by\%20Subject/4364.0.55. 001 2017-18 Main\%20Features Kidney\%20disease 65 .

3. Australian Institute of Health and Welfare [AIHW]. Chronic Kidney Disease (2019). Available at: https://www.aihw.gov.au/reports/chronic-kidneydisease/chronic-kidney-disease-compendium/contents/how-manyaustralians-have-chronic-kidney-disease.

4. Swift O, Vilar E, Farrington K. Haemodialysis. Medicine (2019) 47(9):596602. doi: 10.1016/j.mpmed.2019.06.004

5. Watanabe Y, Yamagata K, Nishi S, Hirakata H, Hanafusa N, Saito C, et al. Japanese Society for Dialysis Therapy Clinical Guideline for "Hemodialysis Initiation for Maintenance Hemodialysis". Ther Apher Dial (2015) 19 Suppl 1 (S1):93-107. doi: 10.1111/1744-9987.12293

6. Kuhlmann MK, Kotanko P, Levin NW. Hemodialysis. Compr. Clin. Nephrol: Elsevier (2010) p:1060-8. doi: 10.1016/B978-0-323-05876-6.00090-3

7. Patel N, Hu SL. Preserving Residual Renal Function in Dialysis: What We Know. Semin. Dial (2015) 28(3):250-8. doi: 10.1111/sdi.12302

8. Vilar E, Farrington K. Emerging Importance of Residual Renal Function in End-Stage Renal Failure. Semin Dial (2011) 24(5):487-94. doi: 10.1111/ j.1525-139X.2011.00968.x

9. Obi Y, Rhee CM, Mathew AT, Shah G, Streja E, Brunelli SM, et al. Residual Kidney Function Decline and Mortality in Incident Hemodialysis Patients. J. Am. Soc. Nephrol: JASN (2016) 27(12):3758-68. doi: 10.1681/ ASN.2015101142

10. Termorshuizen F, Korevaar JC, Dekker FW, van Manen JG, Boeschoten EW, Krediet RT. The Relative Contribution of Residual Renal Function and Adequacy of Dialysis to Survival in Hemodialysis Patients. Hemodialysis Int (2003) 7(1):73-104. doi: 10.1046/j.1492-7535.2003.01214.x

11. Jansen MA, Hart AA, Korevaar JC, Dekker FW, Boeschoten EW, Krediet RT, et al. Predictors of the Rate of Decline of Residual Renal Function in Incident about the importance of maintaining renal residual function in patients receiving haemodialysis, specifically during the patient's first year on haemodialysis. This may affect health outcomes for this patient cohort positively and may have potential to result in a prolonged renal residual function for these patients.

The following table (Table 3) depicts potential future studies resulting from this scoping review.

\section{DATA AVAILABILITY STATEMENT}

The original contributions presented in the study are included in the article/supplementary material. Further inquiries can be directed to the corresponding author.

\section{AUTHOR CONTRIBUTIONS}

US and HK conducted the systematic literature review, performed initial data analysis, selected papers and appraised their quality, read and approved the final manuscript. HD participated in the systematic review, confirmed the analysis and helped to draft the manuscript, read and approved the final manuscript. All authors contributed to the article and approved the submitted version.
Dialysis Patients. Kidney Int (2002) 62(3):1046-53. doi: 10.1046/j.15231755.2002.00505.x

12. de Sequera P, Corchete E, Bohorquez L, Albalate M, Perez-Garcia R, Alique M, et al. Residual Renal Function in Hemodialysis and Inflammation. Ther Apher Dial (2017) 21(6):592-8. doi: 10.1111/1744-9987.12576

13. Chen HC, Chou CY, Jheng JS, Chen IR, Liang CC, Wang SM, et al. Loss of Residual Renal Function is Associated With Vascular Calcification in Hemodialysis Patients. Ther Apher Dial (2016) 20(1):27-30. doi: 10.1111/1744-9987.12376

14. Yao Z, Wang C, Zhang Q, Ma S, Gui B, Duan C. Prevalence of Abdominal Artery Calcification in Dialysis Patients With End-Stage Renal Disease: A Systematic Review and Meta-Analysis. Int Urol Nephrol (2017) 49(11):2061-9. doi: 10.1007/s11255-017-1685-9

15. Steinwandel U, Gibson N, Towell-Barnard M, Parsons R, Rippey JJ, Rosman J. Measuring the Prevalence of Intradialytic Hypotension in a Satellite Dialysis Clinic: Are We Too Complacent? J Clin Nurs (2018) 27(7-8):e1561-e70. doi: 10.1111/jocn.14309

16. Vanholder R, Van Biesen W, Lameire N. A Swan Song for Kt/Vurea. Semin Dial (2019) 32(5):424-37. doi: 10.1111/sdi.12811

17. Mathew AT, Obi Y, Rhee CM, Chou JA, Kalantar-Zadeh K. Incremental Dialysis for Preserving Residual Kidney Function-Does One Size Fit All When Initiating Dialysis? Semin Dial (2018) 31(4):343-52. doi: 10.1111/sdi.12701

18. Poulsen CG, Kjaergaard KD, Peters CD, Jespersen B, Jensen JD. Quality of Life Development During Initial Hemodialysis Therapy and Association With Loss of Residual Renal Function. Hemodial Int (2017) 21(3):409-21. doi: 10.1111/hdi.12505

19. Yapa HE, Purtell L, Chambers S, Bonner A. The Relationship Between Chronic Kidney Disease, Symptoms and Health-Related Quality of Life: A Systematic Review. J Ren Care (2020) 46(2):74-84. doi: 10.1111/jorc.12303

20. Silva LF, Lopes GB, Cunha TO, Protasio BM, Pisoni RL, James SA, et al. Coping With Fluid Restriction and the Quality of Life in Hemodialysis Patients With Very Low or No Daily Urine Output. Int J Artif Organs (2014) 37(6):427-35. doi: 10.5301/ijao.5000329

21. He L, Liu X, Li Z, Abreu Z, Malavade T, Lok CE, et al. Rate of Decline of Residual Kidney Function Before and After the Start of Peritoneal Dialysis. Perit Dial Int (2016) 36(3):334-9. doi: 10.3747/pdi.2016.00024 
22. Caravaca F, Dominguez C, Arrobas M. Predictors of Loss of Residual Renal Function in Peritoneal Dialysis Patients. Perit Dial Int (2002) 22(3):414-7. doi: 10.1177/089686080202200319

23. ANZDATA. ANZDATA Registry. 42nd Report, Chapter 2: Prevalence of Renal Replacement Therapy for End Stage Kidney Disease 2019. Adelaide, South Australia: ANZDATA (2019). Available at: https://www.anzdata.org. au/wp-content/uploads/2020/09/c02_prevalence_2019_ar_2020_v1.0_ 20201111.pdf.

24. Kong J, Davies M, Mount P. The Importance of Residual Kidney Function in Haemodialysis Patients. Nephrol (Carlton) (2018) 23(12):1073-80. doi: 10.1111/nep.13427

25. Blum D, Beaubien-Souligny W, Silver SA, Wald R. Thinking Volume First: Developing a Multifaceted Systematic Approach to Volume Management in Hemodialysis. Can J Kidney Health Dis (2019) 6:2054358119879776. doi: $10.1177 / 2054358119879776$

26. Wang J, Xie X, Yan X, Yang X, Zhang X, Chen J, et al. A Fast Decline of Residual Renal Function in the First Year is a Predictor for Early Withdrawal From Peritoneal Dialysis in Non-Diabetic Patients. Kidney Blood Press Res (2019) 44(1):12-21. doi: 10.1159/000497807

27. Lee Y, Okuda Y, Sy J, Kim SR, Obi Y, Kovesdy CP, et al. Ultrafiltration Rate Effects Declines in Residual Kidney Function in Hemodialysis Patients. Am J Nephrol (2019) 50(6):481-8. doi: 10.1159/000503918

28. Sjolund J, Garcia Anton D, Bayes LY, Hoekstra T, Dekker FW, Munoz Mendoza J. Diuretics, Limited Ultrafiltration, and Residual Renal Function in Incident Hemodialysis Patients: A Case Series. Semin Dial (2016) 29 (5):410-5. doi: 10.1111/sdi.12508

29. Poulsen CG, Kjaergaard KD, Peters CD, Jespersen B, Jensen JD. Quality of Life Development During Initial Hemodialysis Therapy and Association With Loss of Residual Renal Function. Hemodial Int (2017) 21(3):409-21. doi: 10.1111/hdi.12505

30. Mokoli VM, Sumaili EK, Lepira FB, Mbutiwi FIN, Makulo JRR, Bukabau JB, et al. Factors Associated With Residual Urine Volume Preservation in Patients Undergoing Hemodialysis for End-Stage Kidney Disease in Kinshasa. BMC Nephrol (2018) 19(1):68. doi: 10.1186/s12882-018-0865-x

31. Huang SH, Filler G, Lindsay R, McIntyre CW. Euvolemia in Hemodialysis Patients: A Potentially Dangerous Goal? Semin Dial (2015) 28(1):1-5. doi: 10.1111/sdi.12317

32. Ok E, Levin NW, Asci G, Chazot C, Toz H, Ozkahya M. Interplay of Volume, Blood Pressure, Organ Ischemia, Residual Renal Function, and Diet: Certainties and Uncertainties With Dialytic Management. Semin Dial (2017) 30(5):420-9. doi: 10.1111/sdi.12612

33. Mitema D, Jaar BG. How Can We Improve the Quality of Life of Dialysis Patients? Semin Dial (2016) 29(2):93-102. doi: 10.1111/sdi.12467
34. Fang A, Lunardi L, Skilton F, Turner D. Residual Renal Function Among Patients on Haemodialysis and Implications for Clinical Practice. Renal Soc Australasia J (2020) 16(2):44-53. doi: 10.33235/rsaj.16.2.44-53

35. You AS, Kalantar-Zadeh K, Obi Y, Novoa A, Peralta RA, Streja E, et al. Residual Urine Output and Mortality in a Prospective Hemodialysis Cohort. Kidney Int Rep (2020) 5(5):643-53. doi: 10.1016/j.ekir.2020.02.002

36. Mokoli VM, Sumaili EK, Lepira FB, Mbutiwi FIN, Makulo JRR, Bukabau JB, et al. Factors Associated With Residual Urine Volume Preservation in Patients Undergoing Hemodialysis for End-Stage Kidney Disease in Kinshasa. BMC Nephrol (2018) 19(1):68. doi: 10.1186/s12882-018-0865-x

37. Wong J, Kaja Kamal RM, Vilar E, Farrington K. Measuring Residual Renal Function in Hemodialysis Patients Without Urine Collection. Semin Dial (2017) 30(1):39-49. doi: 10.1111/sdi.12557

38. Davenport A. Will Incremental Hemodialysis Preserve Residual Function and Improve Patient Survival? Semin. Dial (2015) 28(1):16-9. doi: 10.1111/sdi.12320

39. Shafi T, Mullangi S, Toth-Manikowski SM, Hwang S, Michels WM. Residual Kidney Function: Implications in the Era of Personalized Medicine. Semin Dial (2017) 30(3):241-5. doi: 10.1111/sdi.12587

40. Agarwal R. Volume Overload in Dialysis: The Elephant in the Room, No One can See. Am J Nephrol (2013) 38(1):75-7. doi: 10.1159/000353107

41. Zoccali C, Torino C, Mallamaci F, Sarafidis P, Papagianni A, Ekart R, et al. A Randomized Multicenter Trial on a Lung Ultrasound-Guided Treatment Strategy in Patients on Chronic Hemodialysis With High Cardiovascular Risk. Kidney Int (2021) 100(6):1325-33. doi: 10.1016/j.kint.2021.07.024

42. Liew A. Perspectives in Renal Replacement Therapy: Haemodialysis. Nephrol (Carlton) (2018) 23(Suppl 4):95-9. doi: 10.1111/nep.13449

Conflict of Interest: The authors declare that the research was conducted in the absence of any commercial or financial relationships that could be construed as a potential conflict of interest.

Publisher's Note: All claims expressed in this article are solely those of the authors and do not necessarily represent those of their affiliated organizations, or those of the publisher, the editors and the reviewers. Any product that may be evaluated in this article, or claim that may be made by its manufacturer, is not guaranteed or endorsed by the publisher.

Copyright (C) 2022 Steinwandel, Kheirkhah and Davies. This is an open-access article distributed under the terms of the Creative Commons Attribution License (CC BY). The use, distribution or reproduction in other forums is permitted, provided the original author(s) and the copyright owner(s) are credited and that the original publication in this journal is cited, in accordance with accepted academic practice. No use, distribution or reproduction is permitted which does not comply with these terms. 